Tersedia online di: http://ejournal-balitbang.kkp.go.id/index.php/JP
e-mail:jurnalpari@gmail.com
JURNAL PARI
Volume 6 Nomor 2 Desember 2020
p-ISSN: 2502-0730
e-ISSN : 2549-0133

\title{
PENGELOLAAN HASIL RISET DI PERPUSTAKAAN BALAI BESAR RISET BUDIDAYA LAUT DAN PENYULUHAN PERIKANAN
}

\author{
Ketut Masiani \\ Balai Besar Riset Budidaya Laut dan Penyuluhan Perikanan, Gondol \\ Diterima tanggal : 01 Desember 2020 Diterima setelah perbaikan : 05 Desember 2020 \\ disetujui terbit : 22 Desember 2020
}

\begin{abstract}
ABSTRAK
Pengelolaan bahan pustaka yang baik akan dapat menjadikan bahan pustaka yang dimiliki perpustakaan menjadi sumber informasi bagi penggunanya. Melalui pengelolaan informasi hasil riset di perpustakaan BBRBLPP diharapkan informasi hasil riset yang dihasilkan bisa memberikan manfaat yang lebih besar baik bagi pemustaka dalam hal ini peneliti BBRBLPP, BBRBLPP sebagai Lembaga induknya maupun masyarakat luas. Salah satu bentuk hasil riset yang dikelola perpustakaan BBRBLPP adalah Karya Tulis IImiah (KTI) yang dihasilkan peneliti BBRBLPP. Pengelolaan KTI dilakukan dengan mengelompokkan KTI berdasarkan komoditas riset, penulis dan tahun terbitnya dan digitalisasi KTI yang masih dalam bentuk tercetak. Sampai saat ini KTI yang dikelola perpustakaan di BBRBLPP sebanyak 1.173 buah yang tersedia dalam bentuk cetak dan digital. Pengelolaan KTI lebih lanjut dilakukan dengan menyediakan layanan OPAC (Online Public Access Catalogue) dengan memanfaatkan aplikasi SLIMS (Senayan Library Management System). Hasil Pengelolaan bahan pustaka KTI di perpustakaan BBRBLPP dapat memberikan informasi terkait jumlah KTI yang terlah dihasilkan per tahun, sebaran topik-topik yang ditulis, serta bisa juga digunakan sebagai salah satu indikator untuk melihat produktivitas tiap peneliti dalam menghasilkan KTI.
\end{abstract}

\section{Kata Kunci: Hasil Riset; Informasi; Karya Tulis IImiah; Pengelolaan}

\section{ABTRACT}

Good management of library collections will make it as sources of information for users. Through the management of research results information in the Institute for Mariculture Research and Fishes Extension (IMRAFE) library, it is hoped that its can provide greater benefits for both the researchers of IMRAFE, IMRAFE as the parent institution and the wider community. One form of research results managed by IMRAFE library is Scientific Paper produced by IMRAFE researchers. Scientific Paper management is done by grouping its base on research commodities, authors and the year of publication and digitization of Scientific Paper that is still in printed form. Scientific Paper managed by IMRAFE library is as many as 1,173 titles that are available in print and digital form. Further Scientific Paper management is done by providing OPAC (Online Public Access Catalogue) services by utilizing SLIMS (Senayan Library Management System) application. Scientific Paper management in IMRAFE library can provide information related to the amount of Scientific Paper produced per year, the spread of written topics, and can also be used as one of the indicators of the researcher productivity on scientific writing.

Keywords: Informatio; Management; Research Results; Scientific Paper 


\section{PENDAHULUAN}

Perpustakaan Balai Besar Riset Budidaya Laut dan Penyuluhan Perikanan (BBRBLPP) merupakan perpustakaan khusus yang memiliki tugas dan fungsi untuk mendukung kegiatan BBRBLPP sebagai sebuah lembaga riset. Sebagaimana disebutkan dalam Peraturan Kepala Perpustakaan Nasional Nomor 14 Tahun 2017 Tentang Standar Nasional Perpustakaan Khusus, Perpustakaan khusus adalah perpustakaan yang diperuntukkan secara terbatas bagi pemustaka di lingkungan lembaga pemerintah, lembaga masyarakat, lembaga pendidikan keagamaan, rumah ibadah, atau organisasi lain.

Tujuan perpustakaan khusus sendiri adalah untuk mendapatkan, mengumpulkan, dan menyajikan segala bentuk informasi yang ada hubungannya dengan suatu subjek yang dapat digunakan oleh departemen atau instansi yang bersangkutan untuk membantu tugas badan induk tempat perpustakaan itu bernaung. Dalam Standar Nasional Perpustakaan (2011) disebutkan bahwa tujuan perpustakaan khusus adalah:

1) Menunjang program lembaga induk;

2) Menunjang penelitian lembaga induk;

3) Menggalakkan minat baca di lingkungan unit kerja lembaga induk;

4) Memenuhi kebutuhan pemustaka di lingkungan perpustakaan.

Dalam lembaga riset perpustakaan memiliki tugas dan fungsi yang sangat penting karena perpustakaan merupakan sumber informasi bagi peneliti dan pengguna lainnya. Selain itu perpustakaan juga bertindak sebagai pengelola informasi, baik yang dihasilkan oleh peneliti maupun informasi dari luar, guna mendukung kegiatan lembaganya. Sebagaimana yang diungkapkan Lupita (2017) bahwa perpustakaan harus mampu memperkenalkan dirinya lebih dari hanya sekedar alternatif dari 'co-working space' melainkan kembali kepada sifat asalnya sebagai institusi penyedia informasi yang valid dan berkualitas. Untuk itu perpustakaan perlu melakukan pengelolaan bahan pustaka yang dimiliki. Pengelolaan bahan pustaka yang baik akan membuat bahan pustaka yang dimiliki perpustakaan menjadi sumber informasi bagi penggunanya. Pengelolaan yang baik diharapkan juga membuat informasi yang dimiliki mudah dan cepat diakses oleh masyarakat. Selain itu perpustakaan juga bisa berperan dalam menyebarkan informasi yang dihasilkan oleh lembaganya sehingga semua informasi yang dihasilkan, yang dimiliki dapat menyebar, diketahui dan dapat dimanfaatkan oleh masyarakat.
Informasi dan publikasi hasil riset merupakan salah satu asset berharga yang dikelola perpustakaan khususnya bagi perpustakaan khusus di sebuah lembaga riset. Hal ini dikarenakan informasi dan publikasi hasil riset merupakan informasi yang bernilai tinggi, yang kebenarannya dapat dipertangungjawabkan serta merupakan informasi yang terbarukan. Hal ini tentunya merupakan suatu keunggulan tersendiri bagi perpustakaan BBRBLPP sebagai perpustakaan khusus di sebuah lembaga riset. Oleh karenanya perpustakaan harus mampu mengelola informasi hasil riset yang dimiliki. Melalui pengelolaan informasi hasil riset ini diharapkan informasi hasil riset yang dihasilkan bisa memberikan manfaat yang optimal kepada pemustaka yaitu peneliti, teknisi, mahasiswa/pelajar, petani, dan lainnya, dapat mendukung tupoksi dari BBRBLPP serta mampu menjadi pusat informasi tentang perikanan budidaya laut. Tujuan penulisan ini yaitu untuk mengetahui sebaran KTI yang dihasilkan peneliti BBRBLPP berdasarkan tahun terbit dan topik KTI

\section{TINJAUAN PUSTAKA}

Pada saat ini informasi merupakan salah satu kebutuhan yang sangat penting dan merupakan bagian yang tidak bisa dilepaskan dalam kehidupan masyarakat. Informasi menjadi sebuah hal penting keberadaannya saat ini karena informasi dapat memiliki pengaruh yang besar dalam tatanan kehidupan masyarakat. Informasi dibutuhkan diberbagai segi kehidupan manusia. Pannen, dalam Tawaf, (2012) menjelaskan bahwa faktor yang mempengaruhi kebutuhan informasi seseorang adalah pekerjaan, kegiatan profesi, disiplin ilmu yang diminati, kebiasaan, lingkungan pekerjaan. Sedangkan menurut Crawford, dalam Devadason, (1996), kebutuhan informasi dapat disebabkan oleh:

1. Work activity (Kegiatan pekerjaan)

2. Discipline/ Field / Area of interest (Disiplin ilmu)

3. Availability of facilities (Tersedianya berbagai fasilitas)

4. Hierarchical position of individuals (Jenjang jabatan individu)

5. Motivation factors for information needs (Faktor motivasi terhadap kebutuhan informasi)

6. Need to take a decision (Kebutuhan untuk mengambil keputusan, kebutuhan untuk mencari gagasan baru)

7. Need to seek new ideas (Kebutuhan untuk menumbuhkan ide-ide baru)

8. Need to validate the correct ones (Kebutuhan untuk mendapatkan informasi yang tepat)

9. Need to make professional contributions (Kebutuhan untuk memberikan kontribusi 
professional)

10. Need to establish priority for discovery etc.

(Kebutuhan untuk melakukan penemuan baru)

Perkembangan teknologi yang terjadi saat ini menimbulkan munculnya beragam sumber informasi dengan menawarkan beragam informasi dan kemudahan akses informasi. Perkembangan teknologi informasi ini telah merubah gaya pengguna informasi dimana dulunya sumber informasi yang digunakan dalam bentuk tercetak mulai beralih ke bentuk digital. Tidak dapat dipungkiri bahwa sumber informasi yang berbetuk digital memberikan kemudahan yaitu mudah diakses dimanapun dan kapanpun. Pengguna dapat menelusuri dan memilih informasi yang diinginkan dengan cepat dan mudah. Munculnya bergam sumber informasi dan perubahan trend pengguna informasi ini merupakan tantangan bagi perpustakaan yang berperan sebagai sumber informasi. Untuk dapat bersaing dengan sumber informasi lainnya maka perpustakaan harus mampu mengubah bentuk informasinya sesuai dengan perkembangan dan tuntutan kebutuhan pengguna salah satunya yaitu mengalihmediakan informasi tercetak menjadi digital.

Perkembangan teknologi informasi yang terjadi saat ini juga memberikan beberapa pengaruh positif dalam pengelolaan informasi di perpustakaan. Dalam bidang informasi Suwanto, (2006) menyebutkan bahwa teknologi informasi dapat berfungsi: sumber asli?

a. Mengatur informasi "Ing-Griyo"(in-house information ) atau informasi yang ada di dalam lembaga informasi tersebut, serta mengusahakannya agar dapat di temu balik.

b. Meng-akses pangkalan data luar (Ektern), yaitu pangkalan data dari lembaga-lembaga lain, maupun belahan dunia lain.

c. Meringankan beban kerja

d. Efisien dan menghemat waktu dan tenaga staf

e. Meningkatkan jasa perpusdokinfo dan fungsifungsi baru.

f. Membangun jaringan kerja dan kerjasama

Keberhasilan suatu perpustakaan dapat dilihat dari kemampuan perpustakaan dalam memenuhi segala kebutuhan informasi pemustakanya, kemampuan pengelola dalam mengelola bahan pustaka yang dimiliki perpustakaan. Hal ini disebabkan karena pengelolaan bahan pustaka yang baik pada perpustakaan akan mampu mengoptimalkan pemanfaatan informasi yang dimiliki perpustakaan oleh pemustaka. Pengelolaan bahan pustaka juga merupakan salah satu kegiatan yang wajib dilakukan oleh pustakawan. Hal ini ditegaskan dalam Undang
Undang Republik Indonesia Nomor 43 Tahun 2007 tentang Perpustakaan yang menyebutkan bahwa perpustakaan adalah institusi pengelola koleksi karya tulis, karya cetak, dan/atau karya rekam secara profesional dengan sistem yang baku guna memenuhi kebutuhan pendidikan, penelitian, pelestarian, informasi, dan rekreasi para pemustaka

Dalam kepustakawanan pengelolaan bahan pustaka dapat diartikan sebagai kegiatan yang berkenaan dengan proses penanganan bahan pustaka yang ada di perpustakaan sehingga dapat diketahui dan dimanfatkan oleh pengguna. Pustakawan memegang peranan penting dalam keberhasilan pengelolaan bahan pustaka atau informasi yang dimilik perpustakaan sehingga informasi yang dimiliki dapat dikelola dengan baik dalam proses penyimpanan, penyebaran dan pemanfaatan lainnya. Pustakawan wajib memiliki keahlian dalam pengelolaan bahan pustaka dan informasi karena hal ini merupakan salah satu indikator dari kualitas pustakawan dalam mengelola perpustakaan. Alayyubi dalam Widiyawati, (2001) menyebutkan bahwa pustakawan yang berkualitas adalah pustakawan yang mampu berperan sebagai agen informasi, ilmuwan, dan pendidik. Sebagai ilmuwan, pustakawan harus mampu memberdayakan informasi bukan sekadar melayankan informasi.

Pengelolaan bahan pustaka/informasi yang dimiliki perpustakaan ini bertujuan agar segala bahan pustaka/ informasi dapat dikenal/diketahui pengguna dan dapat diakses dengan mudah, Tanpa pengelolaan informasi yang tepat maka segala informasi yang dimiliki perpustakaan tidak akan dapat dimanfaatkan oleh pemustakanya. Seperti yang diungkapkan oleh Ikhwan, (2015) kegiatan pengolahan bahan pustaka merupakan unsur utama dari kegiatan yang ada di perpustakaan. Sementara itu menurut Astuti, (2014) pengolahan bahan pustaka merupakan salah satu kegiatan penting yang harus dilakukan oleh suatu perpustakaan sebelum melakukan kegiatan pelayanan kepada pengguna. Dari pendapat tersebut dapat dikatakan bahwa pengelolaan bahan pustaka yang dimilliki suatu perpustakaan merupakan hal yang harus dilakukan sebagai upaya untuk mengoptimalkan pemanfaatan informasi yang ada di perpustakaan.

\section{METODE Sumber Data}

Sumber data yang digunakan dalam analisis ini berasal dari data primer dan sekunder. Data primer yang digunakan diantaranya data artikel/ Karya Tulis Ilmiah (KTI) yang dihasilkan peneliti dari tahun 20012019 yang terbit pada jurnal dan prosiding yang 
terkoleksi di perpustakaan BBRBLPP. Sedangkan data sekunder diperoleh melalui studi pustaka/studi literatur dalam bentuk tercetak maupun online.

\section{Teknik Pengumpulan dan Analisis Data}

Pengumpulan data dilakukan dengan mengumpulkan koleksi perpustakaan yang memuat KTI peneliti BBRBLPP yang terbit tahun 2001-2019. Analisa dilakukan terhadap data yang telah terkumpul dan dikelompokkan berdasarkan tahun terbit, topik atau bidang komoditas yang dibahas dan nama penulis pertama dari KTI tersebut.

\section{Penyajian Data}

Hasil pengolahan dan analisa data disajikan dalam bentuk tabel dan grafik yang memuat informasi bidang penelitian, jumlah tulisan, nama penulis dan hasil analisa.

\section{PEMBAHASAN}

Perpustakaan BBRBLPP merupakan perpustakaan khusus. Sesuai dengan Peraturan Kepala Perpustakaan Nasional Republik Indonesia Nomor 14 Tahun 2017 Tentang Standar Nasional Perpustakaan Khusus, perpustakaan BBRBLPP menjalankan fungsi yaitu:

a) mengembangkan koleksi yang menunjang kinerja lembaga induknya;

b) menyimpan semua terbitan dari dan tentang lembaga induknya;

c) menjadi focal point untuk informasi terbitan lembaga induknya;

d) menjadi pusat referal dalam bidang yang sesuai dengan lembaga induknya;

e) mengorganisasi materi perpustakaan;

f) mendayagunakan koleksi;

g) menerbitkan literatur sekunder dan tersier dalam bidang lembaga induknya, baik cetak maupun elektronik;

h) menyelenggarakan pendidikan pengguna;

i) menyelenggarakan kegiatan literasi informasi untuk pengembangan kompetensi SDM lembaga induknya;

j) melestarikan materi perpustakaan, baik preventif maupun kuratif;

k) ikut serta dalam kerjasama perpustakaan serta jaringan informasi;

I) menyelenggarakan otomasi perpustakaan;

m) melaksanakan digitalisasi materi perpustakaan;

n) menyajikan layanan koleksi digital;

o) menyediakan akses informasi pada tingkat lokal, nasional, regional dan global.
Sebagai pusat referensi, perpustakaan BBRBLPP memberikan layanan berupa penyediaan koleksi yang diperlukan peneliti BBRBLPP sebagai rujukan dalam perencanaan, pelaksanaan penelitian maupun penyampaian hasil penelitiannya. Selain itu juga sebagai pusat referensi bagi teknisi litkayasa, petani, pengusaha, pelaku utama perikanan, pelajar, mahasiswa dan pemustaka lainnya.

Perpustakaan BBRBLPP juga berfungsi sebagai pusat penelitian serta memperlancar pelaksanaan tugas BBRBLPP sebagai instansi induknya. Hal ini sesuai dengan Sulistyo-Basuki (1994) yang mengatakan bahwa perpustakaan khusus berfungsi sebagai pusat referal dan penelitian serta sarana untuk memperlancar pelaksanaan tugas instansi atau lembaga yang bersangkutan. Sedangkan tugas perpustakaan khusus adalah melayani suatu kelompok masyarakat khusus yang memiliki kesamaan dalam kebutuhan dan minat terhadap bahan pustaka dan informasi.

Secara umum bahan pustaka yang dimiliki perpustakaan BBRBLPP didominasi bidang perikanan. Kekhususan dalam koleksi ini merupakan suatu peluang untuk pengembangan perpustakaan sebagai perpustakaan khusus yang memiliki koleksi bidang perikanan dan kelautan.

Salah satu koleksi di BBRBLPP yang sering dibutuhkan oleh pemustaka sebagai referensi adalah Karya Tulis IImiah (KTI) yang dihasilkan peneliti. Oleh karena itu pengelolaan KTI sangat penting untuk dilakukan. Dengan pengelolaaan KTI ini maka akan mempermudah dalam penyimpanan dan penelusuran serta penyebaran informasi hasil penelitian yang terkandung dalam KTI. Dengan pengelolaan KTI ini juga akan dapat digunakan sebagai media untuk menelusuri sejauh mana riset suatu bidang telah dilakukan.

Secara umum pengelolaan KTI dapat memberikan beberapa manfaat diantaranya:

1. Bahan pustaka KTI dapat tersimpan dengan baik

2. Meningkatkan ketertelusuran atau temu kembali terdap suatu infrmoasi yang terkandung pada KTI

3. Mempermudah penyebaran informasinya

4. Mempermudah akses informasi oleh pengguna

5. Database hasil riset

Karya tulis ilmiah dalam dunia riset merupakan salah satu bukti otentik, indikator keberhasilan seorang peneliti dalam menjalankan profesinya sebagai peneliti. KTI ini dapat juga digunakan sebagai identitas suatu negara dan sebagai media peningkatan citra suatu bangsa dimata dunia sehingga 
KTI merupakan salah satu asset penting suatu negara yang membutuhkan pengelolaan yang baik dan benar. KTI juga merupakan salah satu bentuk kekayaan suatu bangsa sebagai bentuk kekayaan atau asset tak berwujud sehingga perlu dikelola dengan baik.

KTI yang dihasilkan oleh peneliti perlu dikelola secara baik sehingga dapat menjadi informasi yang dapat diakses dan dimanfaatkan oleh pengguna baik dalam dunia riset, pendidikan, ataupun dalam bidang usaha pengembanan budidaya perikanan. Karya tulis ilmiah yang dihasilkan peneliti BBRBLPP merupakan hasil penelitian berbagai komoditas dalam bidang perikanan khususnya budidaya laut. KTI ini telah dipublikasikan di berbagai media baik cetak maupun non cetak diantaranya publikasi jurnal yang diterbitkan pada Tabel 1 di bawah ini.
Tabel 1. Data KTI yang dikelola Perpustakaan BBRBLPP dilihat dari topik/komoditasnya rampai, dan dalam bentuk buku. nasional, internasional serta di media prosiding, bunga

Pengelolaan KTI yang ada di perpustakaan BBRBLPP dilakukan dengan pengelompokan KTI yang dimiliki. Pengelompokan KTI dilakukan berdasarkan, komoditas riset, penulis, dan tahun terbitnya. Pengelompokan berdasarkan komoditas ini merupakan pengelolaan atau pengelompokkan KTI berdasarkan jenis ikan dan topik yang dibahas dalam KTI tersebut. Dari data yang dikumpulkan dalam kurun waktu 2001 sampai dengan 2019 dihasilkan data bahwa berdasarkan komoditas riset KTI yang ada di BBRBLPP terbagi menjadi 21 kelompok. Sebaran KTI yang dikelola perpustakaan BBRBLPP berdasarkan topik komoditas hasil riset yang dibahas dapat dilihat

\begin{tabular}{lc}
\hline Topik/Komoditas & Jumlah Tulisan \\
\hline Penyakit dan Kesling & 172 \\
Genetik dan Bioteknologi & 124 \\
Pakan dan Nutrisi & 106 \\
Kerapu Bebek & 79 \\
Kerapu Sunu & 71 \\
Pakan alami & 60 \\
Bandeng & 56 \\
Abalon & 55 \\
Ikan Hias & 48 \\
Kuwe & 45 \\
Lingkungan & 45 \\
Udang & 36 \\
Tuna & 35 \\
Kerapu Macan & 32 \\
Kerapu Hybrid & 31 \\
Kakap merah & 29 \\
Cobia & 22 \\
Tiram Mutiara & 20 \\
Lobster & 19 \\
Kepiting bakau & 18 \\
Kerapu Pasir & 17 \\
Rajungan & 17 \\
Bawal & 16 \\
Kerapu lumpur & 16 \\
Napoleon & 16 \\
Teripang & 8 \\
\hline
\end{tabular}

Dari Tabel 1 terlihat bahwa KTI yang dikelompokkan dalam topik komoditas riset Penyakit Ikan dan Kesehatan Lingkungan memiliki jumlah paling banyak yaitu sebanyak 172 judul dan yang paling sedikit adalah KTI dalam kelompok komoditas Teripang yaitu sebanyak 8 judul.

Pengelompokan KTI juga dilakukan berdasarkan tahun terbit dari KTI yang dihasilkan oleh peneliti.
Hasil pengelompokan KTI BBRBLPP berdasarkan tahun terbitnya dapat dilihat pada Gambar 1.

Dari grafik diatas terlihat bahwa jumlah terbitan KTI BBRBLPP paling banyak terdapat pada Tahun 2012 yaitu sebanyak 103 judul dan yang paling sedikit adalah pada tahun 2019 sebanyak 25 judul. Dari data tersebut juga terlihat bahwa rata - rata KTI yang dihasilkan peneliti BBRBLPP per tahun dalam kurun waktu 2001-2019 adalah sebanyak 65 judul KTI. 
Pengelompokan KTI BBRBLPP berdasarkan penulisnya dilakukan dengan mengumpulkan tulisan tulisan yang dihasilkan peneliti BBRBLPP berdasarkan nama penulis pertama dari KTI yang dimaksud. Hasil pengelompokan KTI berdasarkan penulisnya dapat dilihat pada gambar 1 .

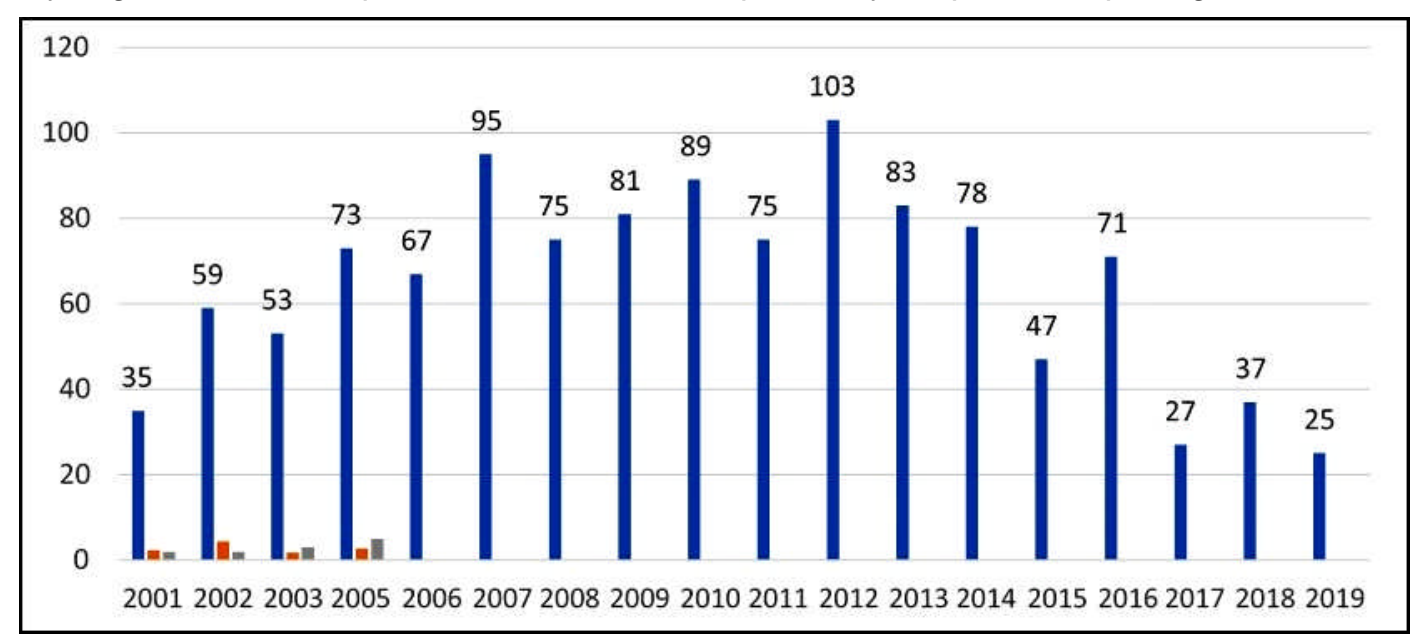

Gambar 1. KTI yang dikelola Perpustakaan BBRBLPP berdasarkan tahun terbitnya.

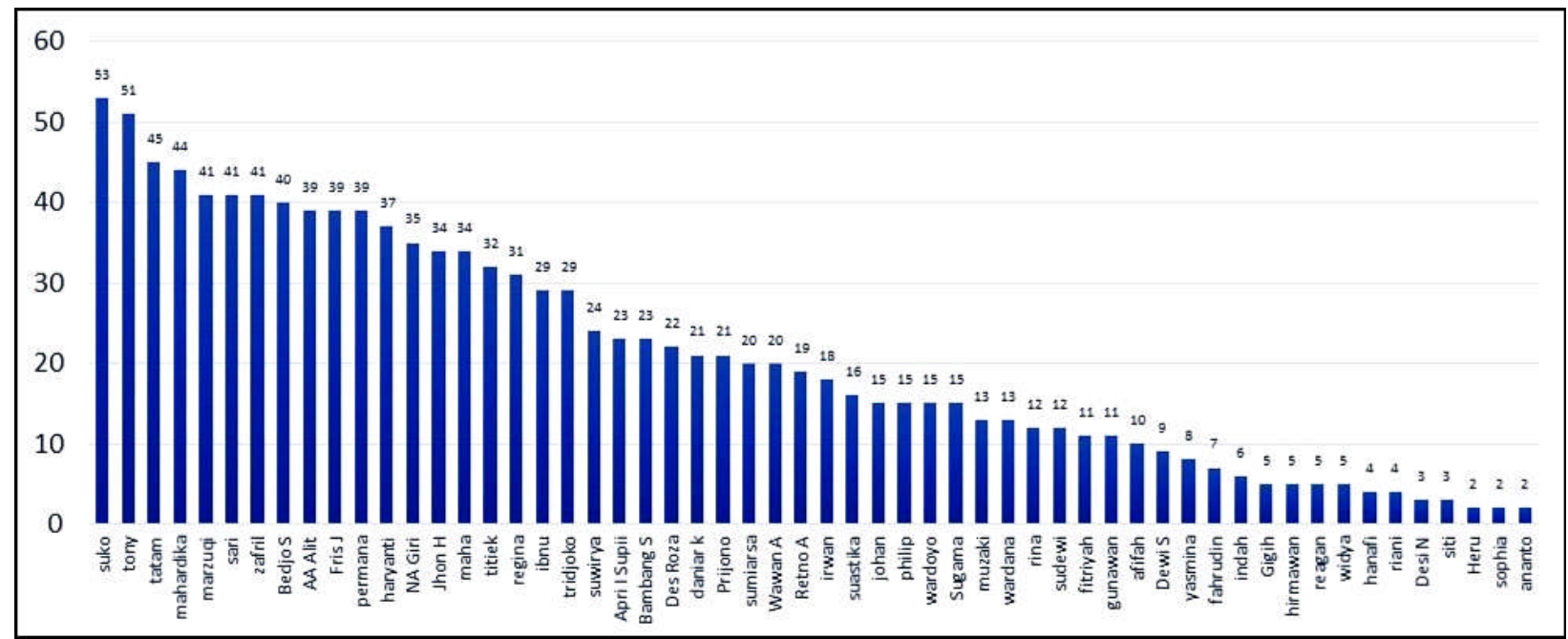

Gambar 2. Pengelompokan KTI berdasarkan nama penulis pertamanya.

Dari Gambar 2 di atas terlihat bahwa terdapat perbedaan jumlah KTI yang dihasilkan masing masing peneliti. Hal ini mungkin dapat juga dipergunakan untuk menunjukkan produktifitas masing - masing peneliti dalam menghasilkan KTI cukup bervariasi. Jumlah penulis, jumlah KTI, nilai rata - rata, maksimum dan minimum KTI yang dihasilkan penulis/peneliti di BBRBLPP dalam kurun waktu tahun 2001 -2019 dapat dilihat pada Tabel 2.

Tabel 2. Jumlah penulis, jumlah KTI, nilai rata - rata, maksimum dan minimum KTI per penulis di BBRBLPP dalam kurun waktu tahun $2001-2019$

\begin{tabular}{clcc}
\hline No & & Uraian & Nilai \\
\hline 1 & Jumlah Penulis & 56 \\
2 & Jumlah KTI & 1173 \\
3 & Rata-Rata & 20 \\
4 & Maksimum & 53 \\
5 & Minimum & 2 \\
\hline
\end{tabular}

Tabel 2 menunjukkan bahwa jumlah KTI yang dihasilkan peneliti BBRBLPP dalam kurun waktu 2001-2019 sebanyak 1173 judul dengan 56 nama penulis pertama yang berbeda. Dari data tersebut juga terlihat bahwa rata rata KTI yang dihasilkan satu orang peneliti di BBRBLPP dalam kurun waktu tersebut adalah sebanyak $20 \mathrm{KTI}$ per penulis. Dilihat dari nama penulis pertama pada KTI BBRBLPP terlihat bahwa 
satu peneliti bisa menghasilkan $\mathrm{KTI}$ (sebagai penulis pertama) tertinggi hingga sejumlah $53 \mathrm{KTI}$ dan terendah sejumlah $2 \mathrm{KTI}$.

Sebagai lembaga riset dalam budidaya laut, maka perpustakaan BBRBLPP menjadi rujukan dalam informasi tentang perikanan budidaya laut. Sampai saat ini KTI hasil riset peneliti BBRBLPP yang dikelola perpustakaan di BBRBLPP sebanyak 1.173 judul yang sudah tersedia dalam bentuk cetak dan digital. Sesuai dengan tuntutan perkembangan Teknologi Informasi saat ini, KTI yang berbentuk cetak dilakukan alih media publikasi ke bentuk digital. KTI yang masih berbentuk cetak discan sehingga selain dalam bentuk cetak juga tersedia dalam bentuk digital.

Sebagai upaya untuk memenuhi tuntutan penyediaan informasi yang mudah diakses yang menjadi kebutuhan pemustaka saat ini, perpustakaan BBRBLPP mengelola sumber informasi (KTI) agar dapat diaskes secara terbuka oleh pengguna sehingga pengguna dengan mudah dan cepat dapat memperoleh informasi dari KTI yang dihasilkan oleh peneliti BBRBLPP. Dengan memanfaatkan aplikasi yang tersedia saat ini yaitu aplikasi SLIMS (Senayan Library Management System), perpustakaan BBRBLPP telah menyediakan layanan OPAC (Online Public Access Catalogue) sehingga pemustaka dapat menelusuri informasi koleksi termasuk KTI yang ada di perpustakaan kapan dan dimanapun secara online. Dengan layanan ini pengelolaan KTI diharapkan akan dapat memberikan manfaat yang maksimal kepada pengguna.

\section{KESIMPULAN}

Pengelolaan karya tulis ilmiah (KTI) pada perpustakaan khusus merupakan kegiatan yang sangat penting. Pengelolaan bahan pustaka berupa $\mathrm{KTI}$ dapat memberikan kemudahan dalam pengelolaan informasi, dan pelayanan informasi kepada pengguna serta dapat dipergunakan sebagai informasi kegiatan riset yang telah dilakukan oleh lembaga induknya. Pengelolaan KTI di perpustakaan BBRBLPP dapat memberikan informasi terkait jumlah KTI yang telah dihasilkan per tahun, sebaran topik-topik yang ditulis, serta bisa juga digunakan sebagai salah satu indikator untuk melihat produktivitas tiap peneliti dalam menghasilkan KTI. Dari hasil analisa diperoleh bahwa $\mathrm{KTI}$ terbanyak yang dihasilkan peneliti BBRBLPP yaitu pada tahun 2012 dengan jumlah KTI sebanyak 103 Judul. Sedangkan topik yang paling banyak ditulis dari tahun 2001 sampai dengan tahun 2019 yaitu tentang Penyakit dan Kesehatan Lingkungan.

\section{DAFTAR PUSTAKA}

. 2017. Peraturan Kepala Perpustakaan Nasional Nomor 14 Tahun 2017 Tentang Standar Nasional Perpustakaan Khusus, Perpustakaan khusus

2011. Standar Nasional Perpustakaan Khusus. Standar Nasional Perpustakaan Khusus. Jakarta. Perpustakaan Nasional RI,

2007. Undang Republik Indonesia Nomor 43 Tahun 2007 tentang Perpustakaan

Adhar, H.D. 2012. Pentingnya Teknologi Informasi Ada Di Lingkungan Perpustakaan. Jurnal Iqra' Volume 06 No.02 Okt, 2012. Medan. Universitas Islam Negeri Sumatera Utara

Astuti, A. 2014. Pengolahan Bahan Pustaka di Perpustakaan SMK Muhammadiyah 3 Yogyakarta. Skripsi.Yogyakarta. UIN Sunan Kalijaga

Darmono.2001. Manajemen Perpustakaan. Jakarta. Grasindo Eastwood

Devadason, F.J. 1996. AMethodology for the Identification of Information Needs ofUsers,62nd IFLA General Conference -Conference Proceedings August 25-31.

Ikhwan, S. M. 2015. Proses Pengolahan Bahan Pustaka di UPT Perpustakaan Universitas Mataram

Lupita, J dkk. 2017. Perpustakaan dan co-working space Universitas Airlangga di Surabaya. Surabaya. Jurnal Edimensi Arsitektur, V (1), p. 433-440.

http://download.garuda.ristekdikti.go.id/ article.php? article $=936831 \& \mathrm{val}=6501 \&$ title $=$ Perpustaka a $\% 20$ d a n \% $20 \mathrm{Co}$ Working\%20Space $\% 20$ Universitas $\% 20 \mathrm{~A}$ irlangga\%20di\%20Surabaya. Diakses tanggal 28 Agustus 2020

Sulistyo-Basuki. 1994. Periodisasi Perpustakaan Indonesia. Bandung: PT. Remaja Rosdakarya

Suwanto, S.A. 2006. Teknologi Informasi Untuk Perpustakaan Dan Pusat Dokumentasi Dan Informasi http://eprints.undip.ac.id/3619/2/ Teknologi_informasi_BU_ATIK.pdf . Diakses tanggal 24 September 2020 
Tawaf. 2012. Kebutuhan Informasi Manusia: Sebuah Pendekatan Kepustakaan. Riau . Universitas Negeri Sultan Syarif Kasim Riau

http://ejournal.uin-suska.ac.id/index.php/ Kutubkhanah/article/view/249/234. Diakses tanggal 23 Agustus 2020

Widiyawati, A.T. 2015. Peran Perpustakaan Dalam Mendukung Pendidikan Sebagai Upaya
Pengembangan Sumber Daya Manusia Menyongsong Masyarakat Asean 2015.Malang. Universitas Brawijaya, Malang.

http://Anitatriwidiyawati.Lecture.Ub.Ac.Id/Files/2015/ 07/Peran-Perpustakaan-Dalam-MendukungPendidikan-Sebagai-Upaya-PengembanganSumber-Daya-Manusia-MenyongsongMasyarakat-Asean-2015.Pdf . Diakses tanggal 23 Agustus 2020 